\title{
Tephritids of knapweeds, starthistles and safflower: results of a host choice experiment and the taxonomy of Terellia luteola (Wiedemann) (Diptera: Tephritidae)
}

\author{
Ian M. White \\ CAB International Institute of Entomology, London, UK \\ Kerstin Groppe \\ $\mathrm{CAB}$ International Institute of Biological Control, 1 Chemin des \\ Grillons, CH-2800, Delémont, Switzerland \\ Rouhollah Sobhian \\ Biological Control of Weeds Laboratory-Europe, USDA-ARS, \\ American Embassy, Agriculture, APO New York 09794, USA
}

\begin{abstract}
A host choice experiment was carried out to determine the host range of some potential biological control agents of yellow starthistle (Centaurea solstitialis), a Mediterranean plant which has become a serious rangeland weed in western USA. This paper describes the results of that experiment and discusses its taxonomic implications. The experiment confirmed the extreme host specificity of some species. However, two reputedly polyphagous species, Acanthiophilus helianthi (Rossi) and Urophora quadrifasciata (Meigen), attacked a narrower range of hosts than expected. The results of this and similar host choice experiments are discussed and it is concluded that this sort of anomaly can be caused by the existence of host races, unrecognized sibling species, or by varieties of plants naturally resistant to attack. These complex patterns of host relationship highlight the need to interpret host catalogue data cautiously, as they oversimplify complex biological systems. The identity of one species reared in the experiment, Terellia luteola (Wiedemann), is discussed; a key is presented for its separation from other Terellia species, and it is removed from synonymy with $T$. colon (Meigen).
\end{abstract}

\section{Introduction}

Centaurea solstitialis L. (yellow starthistle), C. maculosa Lam. (spotted knapweed) and C. diffusa Lam. (diffuse knapweed) are introduced weeds of rangeland in the United States and Canada (Harris \& Myers, 1984; Maddox, 1981). They have been targeted for biological

Correspondence: Dr I. M. White, CAB International Institute of Entomology, 56, Queen's Gate, London, SW7 5JR, UK. control, and several insect species have been investigated and released as control agents. Amongst the Tephritidae, Urophora affinis (Frauenfeld) and $U$. quadrifasciata (Meigen) are now well established on diffuse and spotted knapweed in western Canada and adjoining areas of the USA, and the use of Urophora spp. for biological weed control has been reviewed by White \& Clement (1987). A field experiment was carried out to determine the host specificity of some potential biocontrol agents of Centaurea spp., namely, $U$. sirunaseva (Hering), 
Table 1. Number of female/male flies reared from each test host species. Values in parenthesis are the number of individuals per 1000 capitula, given as an indicator of population density.

\begin{tabular}{|c|c|c|c|c|c|c|c|}
\hline \multicolumn{8}{|c|}{ Test plant species } \\
\hline & $\begin{array}{l}\text { Carthamus } \\
\text { tinctorius }\end{array}$ & $\begin{array}{l}\text { Centaurea } \\
\text { diffusa }\end{array}$ & $\begin{array}{l}\text { Centaurea } \\
\text { maculosa }\end{array}$ & $\begin{array}{l}\text { Centaurea } \\
\text { solstitialis }\end{array}$ & $\begin{array}{l}\text { Cirsium } \\
\text { creticum }\end{array}$ & $\begin{array}{l}\text { Cynara } \\
\text { scolymus }\end{array}$ & $\begin{array}{l}\text { Helianthus } \\
\text { annuus }\end{array}$ \\
\hline capitula & 301 & 36150 & 4345 & 5064 & 3850 & 41 & 85 \\
\hline A. helianthi & $\begin{array}{l}119 / 129 \\
(824)\end{array}$ & $\begin{array}{l}136 / 123 \\
(7)\end{array}$ & $\begin{array}{l}5 / 6 \\
(3)\end{array}$ & $0 / 0$ & $\begin{array}{l}22 / 29 \\
(13)\end{array}$ & $0 / 0$ & $0 / 0$ \\
\hline C. australis & $0 / 0$ & $0 / 0$ & $0 / 0$ & $\begin{array}{l}186 / 195 \\
(75)\end{array}$ & $0 / 0$ & $0 / 0$ & $0 / 0$ \\
\hline T. fuscicornis & $0 / 0$ & $0 / 0$ & $0 / 0$ & $0 / 0$ & $0 / 0$ & $\begin{array}{l}2205 / 2571 \\
(116488)\end{array}$ & $0 / 0$ \\
\hline T. luteola & $\begin{array}{l}6 / 8 \\
(47)\end{array}$ & $0 / 0$ & $0 / 0$ & $0 / 0$ & $0 / 0$ & $0 / 0$ & $0 / 0$ \\
\hline U. quadrifasciata & $0 / 0$ & $\begin{array}{l}139 / 112 \\
(7)\end{array}$ & $\begin{array}{l}8 / 4 \\
(3)\end{array}$ & $0 / 0$ & $0 / 0$ & $0 / 0$ & $0 / 0$ \\
\hline U. sirunaseva & $0 / 0$ & $0 / 0$ & $0 / 0$ & $\begin{array}{l}28 / 31 \\
(12)\end{array}$ & $0 / 0$ & $0 / 0$ & $0 / 0$ \\
\hline U. stylata & $0 / 0$ & $0 / 0$ & $0 / 0$ & $0 / 0$ & $\begin{array}{l}40 / 30 \\
(18)\end{array}$ & $0 / 0$ & $0 / 0$ \\
\hline
\end{tabular}

and the weevils Larinus minutus Gyllenhal and L. curtus Hochhut (Coleoptera, Curculionidae). During the course of this experiment over 7,000 individuals, representing seven tephritid species, were also reared. The results (table 1) emphasized the narrow host specificity of many of these flies, but the supposedly polyphagous species avoided some plants which they might have been expected to attack. In addition, a few individuals of a Terellia $\mathrm{sp}$. were reared from Carthamus tinctorius L. and these were found to be T. luteola (Wiedemann), a species formerly confused with $T$. colon (Meigen). The biocontrol aspects of this field experiment will be discussed elsewhere (Groppe et al., in prep.).

\section{Field experiment}

A field experiment using a randomized block design was carried out at the University of Thessaloniki farm near Thermi, Greece, in 1988 (by KG \& RS). The design consisted of seven plant species replicated in seven rows (49 blocks), each block $(2 \times 2 \mathrm{~m})$ containing three free growing specimens of one plant species. The following plants were selected, either because they were recorded hosts of the investigated species, or because they were related crop plants: Centaurea maculosa, C. diffusa, C. solstitialis, Cirsium creticum (Lam.) D'Urv. (a thistle), Carthamus tinctorius L. (Hartmann cultivar of the crop safflower), Cynara scolymus L. (artichoke) and Helianthus annuus L. (sunflower). All of these plants belong to the family Asteraceae (=Compositae), and with the exception of $H$. annuus, they all belong to the tribe Cardueae. The plants used were all derived from indigenous Greek populations, except for the safflower and artichoke, which were commercial varieties cultivated in California.
$U$. sirunaseva was deliberately introduced into each block, as follows: in May, 50 dry overwintered C. solstitialis flower heads, $5 \%$ containing pupae, were placed on the ground in the centre of each block; in June, 50 postflowering stage heads, $9 \%$ containing mature larvae or pupae, were placed in the centre of each block. These rates of infestation were determined by dissecting a sample of 100 heads from each of the two batches. Other hosts were attacked by flies derived from surrounding natural populations.

The capitula were harvested at weekly intervals during the seed formation stage. About 50,000 seedheads were harvested and all insects emerging were collected. The tephritids were sorted at Delémont and representatives of each species were sent to CIE for verification (CIE coll. A20013). The total number of males and females of each species reared, and the number of capitula collected from each host species, are recorded in table 1.

\section{Results and discussion of host specificity experiment}

Chaetorellia australis Hering, Terellia fuscicornis (Loew), T. luteola, U. sirunaseva (Hering) and U. stylata (Fabricius) each attacked a single included plant species, which was the expected result based on our existing knowledge of their hosts (White \& Korneyev, 1989; White \& Marquardt, 1989). However, Acanthiophilus helianthi (Rossi) and $U$. quadrifasciata (Meigen), each attacked a narrower range of the included plant species than would have been predicted from existing knowledge.

$A$. helianthi has about 50 recorded host plants, most of which belong to the tribe Cardueae, suggesting that this fly has the ability to attack any member of that tribe. However, in this experiment $A$. helianthi attacked only 
four of the six Cardueae species tested and showed a strong preference for safflower, Carthamus tinctorius. The rejected plants were yellow starthistle, which is a known host in France (Zwölfer, 1965), and artichoke, at least one cultivar of which is a known host in Egypt (Saddik \& Miniawi, 1978). In Britain A. helianthi has been recorded only on Centaurea nigra L., indicating that it is probably monophagous in that area (White, 1988)

$U$. quadrifasciata attacks a wide range of Centaurea spp. and White \& Korneyev (1989) divided this species into three subspecies, each of which is distinct in terms of host choice, and fairly distinct in morphology and geographical distribution; the possibility that these 'subspecies' are distinct biological species has been discussed by White \& Korneyev (1989). U. quadrifasciata quadrifasciata is a central and western European subspecies, which is usually associated only with knapweeds, such as $C$. diffusa and C. maculosa, both of which proved to be hosts in the field experiment. The other two subspecies of $U$. quadrifasciata are associated with starthistles in the Mediterranean and Middle Eastern areas, but in Italy yellow starthistle (C. solstitialis) is attacked by flies morphologically inseparable from $U$. quadrifasciata quadrifasciata.

The failure of the Thermi populations of $A$. helianthi and $U$. quadrifasciata to attack plants which are known to be important hosts elsewhere, tempts speculation that these tephritids are both species complexes, but variation in the host plants could also explain the observations. Some varieties of safflower have been developed for resistance to $A$. helianthi attack in India (Jakhmola \& Yadav, 1980) and similarly, it is possible that the form of yellow starthistle and artichoke grown in the experiment at Thermi had natural resistance to attack. White \& Clement (1987) reported another experiment carried out in Thermi, and an experiment carried out in Rome, Italy, designed to test the response of Urophora spp. to yellow starthistle of different origins; they showed that $U$. jaculata Rondani attacks yellow starthistle from only Italy and southern Greece, and that $U$. sirunaseva attacks plants derived only from the Thermi area, Moldavian SSR and Turkey, plus the adventive North American plants. In contrast, White \& Clement (1987) found that Italian $U$. quadrifasciata quadrifasciata (from yellow starthistle) could attack both Italian and American yellow starthistle, indicating that Italian $U$. quadrifasciata quadrifasciata and $U$. jaculata each differ in their response to plants of different origins. The Thermi experiment described in this paper, only confirms that $U$. quadrifasciata quadrifasciata (a knapweed associated population) will not attack yellow starthistle of the type found at Thermi; it does not show that the Thermi population cannot attack some other varieties of yellow starthistle.

The combined results of the field experiments carried out at Rome and Thermi indicate that host plant catalogues which simply list the tephritids found developing on specific plant species have to be interpreted cautiously for various reasons, including that they oversimplify complex biological systems in which the plants, as well as the insects, are subject to variation, manifested as local differences in host selection. Failure to consider the potential complexity of a tephritid host-plant association led to the introduction of $U$. jaculata (misidentified as $U$. sirunaseva) into northern California in 1969, 1976 and 1977 , before it had been shown that $U$. jaculata would not attack the form of yellow starthistle adventive in North America (White \& Clement, 1987).

\section{Status of Terellia luteola}

Terellia luteola is a safflower associated tephritid that has previously been confused with $T$. colon (Meigen), a knapweed associated species, and the opportunity is taken to resolve this confusion

\section{Terellia luteola (Wiedemann) stat. $\mathbf{n}$.}

Trypeta luteola Wiedemann, 1830: 491.

Orellia colon (Meigen); Kugler \& Freidberg, 1975: 63; Foote, 1984: 105 (in part) [misidentification]

Terellia serratulae (Linnaeus); Efflatoun, 1924: 76 [misidentification]

During the search for suitable biocontrol agents for yellow starthistle, it has been necessary to eliminate species which can attack the crop safflower, Carthamus tinctorius. Carthamus spp. tend to have a very similar tephritid fauna to that of the starthistles and it is important to be certain that an agent introduced for the biocontrol of yellow starthistle will not become a pest of safflower. Consequently, weed biocontrol specialists have taken an interest in the tephritid fauna of safflower and wild Carthamus spp. One of the flies regularly reared from Carthamus spp. is very similar to Terellia colon and was initially misidentified as that species, but dissection of the aculeus showed that it was clearly a different species.

In the recent Catalogue of Palaearctic Diptera, Foote (1984) lists Trypeta luteola as a synonym of Orellia colon; the latter species has more recently been transferred to Terellia Robineau-Desvoidy by Korneyev (1985). Terellia luteola was described from Egypt, suggesting that it was likely to be an existing name for the Carthamus associated species and that was confirmed by examination of the holotype female (Forschungsinstitut Senckenberg, Frankfurt). Other specimens of $T$. luteola were examined from the collection of The Natural History Museum, London, and The National Museum of Natural History (Smithsonian Institution), Washington, D.C. All other nominal species listed as synonyms of $T$. colon by Foote (1984) are assumed to be syonyms of that species. Type material of the following nominal species was examined: Trypeta colon Meigen (19, presumed syntype), Sciomyza picta Meigen (10, presumed syntype) (both in Musum National d'Histoire Naturelle, Paris) and Tripeta nebrodesia Rondani (1ㅇ, presumed syntype; Museo Zoologico dell'Università degli Studi di Firenze).

Terellia luteola has been examined from the following hosts: Carthamus dentatus in Greece and C. tinctorius (safflower) in Greece, Israel and Italy; some non-reared material was examined from Israel and Tunisia. In addition, Kugler \& Freidberg (1975) record it (as Orellia colon) from C. glaucus M.B., C. lanatus L. and C. tenuis (Boiss.) Bornm. in Israel. The only specimens associated with another host genus were from Israel $\left(19,10^{7}\right.$, Golan Heights, Smin Field School, May 1987, leg. IMW \& A. Freidberg), reared from a large sample of capitula of Centaurea (Lopholoma) crocodylium L.; further study is needed to confirm that this is a normal host for T. luteola. 


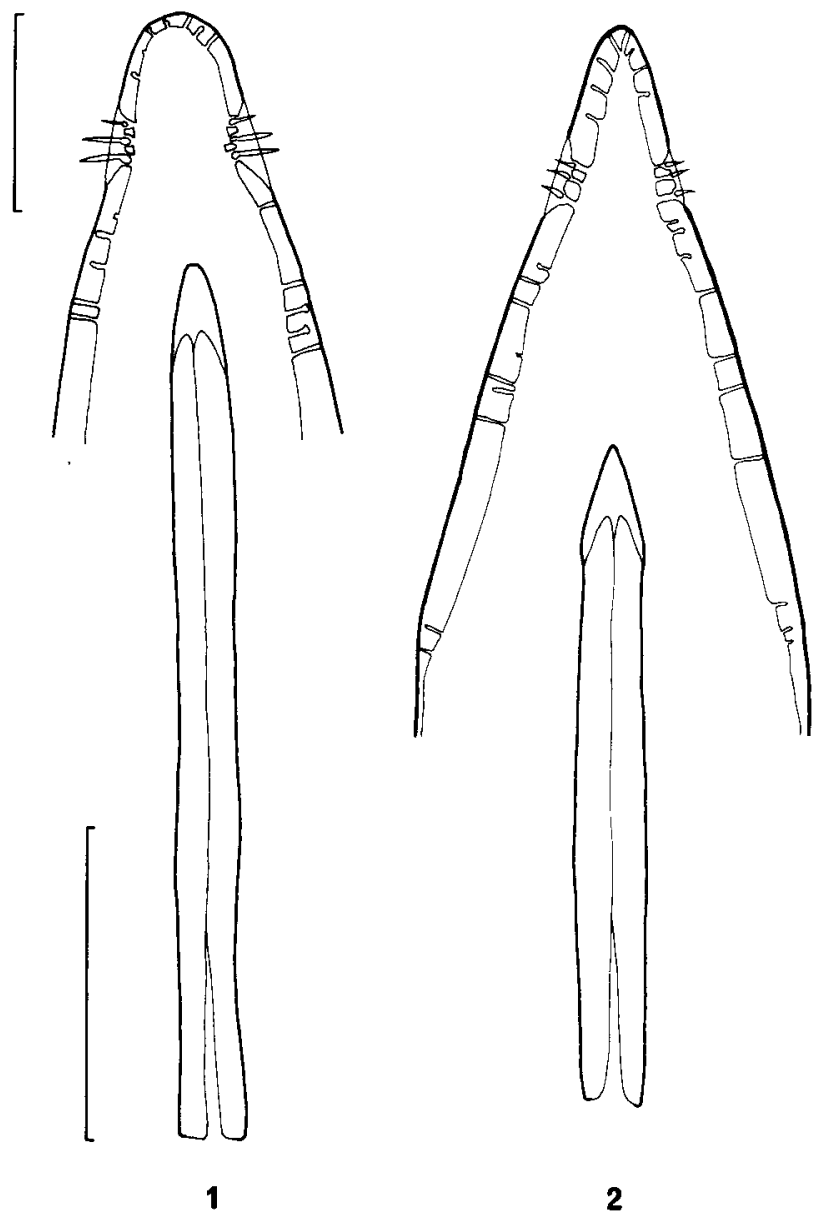

Figs. 1-2, aculei, dorsoventral outlines with apex detail; 1, Terellia luteola; $2, T$. colon.

$T$. colon and T. luteola form the T. colon species group of Korneyev (1985), and the following key separates them from other members of the genus:

1. Wing largely or entirely hyaline, at most with an infuscate patch covering the apices of veins $R_{2+3}$ and $R_{4+5}$; distal section of vein $M$ less than twice as long as preceding section; prescutellar acrostichal setae based on a dark area; pleurae without a series of pale yellow and orange stripes; setulae on abdominal tergite 3 black.

colon group 2

Wing usually patterned; if hyaline, then without the above combination of characters.

other Terellia spp.

2. Aculeus with a narrowly rounded apex (fig. 1). Scutum pale coloured between the supra-alar and intra-alar setae. Wing entirely hyaline. [Aculeus length 2.2-3.5 mm; wing length 3.4-5.2 $\mathrm{mm}$ ].

.. luteola (Wiedemann)

Aculeus apex more acute (fig. 2). Scutum usually black between the supra-alar and intra-alar setae, either due to a black lateral stripe, or because the black central area of the scutum extends laterally as far as the supra-alar setae (White, 1988, fig. 111). Wing of male usually with an infuscate mark covering the apices of veins $R_{2+3}$ and $R_{4+5}$ (White, 1988, fig. 228); female at most with a small mark at the apex of vein $R_{2+3}$ (White, 1988, fig. 227). [Aculeus length 2.1$3.0 \mathrm{~mm}$; wing length $3.9-5.4 \mathrm{~mm}$. Larvae develop in the capitula of Centaurea (Lopholoma) spp., usually on C. (L.) scabiosa L. in Europe; also on C. (L.) collina L. in southern France, and recorded from temperate Asia as far east as Siberia].

colon (Meigen)

\section{Acknowledgements}

We are grateful to the following curators for allowing us to examine specimens in their charge: Dr L. Matile (Paris), Dr A.L. Norrbom (Washington), A.C. Pont (London), W. Tobias (Frankfurt) and Mrs S. WhitmanMascherini (Florence). We also wish to thank Dr A. Friedberg (Tel Aviv University) for helping IMW to collect Tephritidae in Israel, and the authorities at the University of Thessaloniki who provided facilities for the field experiment.

\section{References}

Efflatoum, H.C. (1924) A monograph of Egyptian Diptera, part II, Fam Trypaneidae. Mémoires de la Société Royale Entomologique d'Egypte 7(2) (1923), 152-156.

Foote, R.H. (1984) In: Soós, A. \& Papp, L. (Eds). Catalogue of Palaearctic Diptera. Family Tephritidae (Trypetidae) 9, 66-149. Budapest.

Harris, P. \& Myers, J.H. (1984) Centaurea diffusa Lam. and C. maculosa Lam. s.lat., diffuse and spotted knapweed (Compositae) pp. 127-137 in Kelleher, J.S. \& Hulme, M.A. (Eds) Biological control programmes against insects and weeds in Canada 1969-1980. Farnham Royal, Berks, UK, Commonwealth Agricultural Bureaux.

Jakhmola, S.S. \& Yadav, H.S. (1980) Incidence of and losses caused by capsule fly Acanthiophilus helianthi Rossi in different varieties of safflower. Indian Journal of Entomology $42,48-53$.

Korneyev, V. (1985) Fruit flies of the tribe Terelliini (Diptera, Tephritidae) in the USSR. Entomologicheskoe Obozrenie 64, 626-644. [in Russian: English translation in Entomological Review, Washington 65, 35-55.]

Kugler, J. \& Freidberg, A. (1975) A list of the fruitflies (Diptera: Tephritidae) of Israel and nearby areas, their host plants and distribution. Israel Journal of Entomology 10, 51-72.

Maddox, D.M. (1981) Introduction, phenology, and density of yellow starthistle in coastal, intercoastal, and central valley situations in California. Agricultural Research Service, U.S. Department of Agriculture ARR-W-20 July, 1-33.

Saddik, A. \& Miniawi, S.F. El- (1978) A study on infestation of artichoke Cynara cardunculus v. scolymus L. by looper caterpillars and other pests. Proceedings of the IV Conference of Pest Control, 1978, Plant Protection Research Institute, Agricultural Research Centre, Dokki, Egypt 179-187.

White, I.M. (1988) Tephritid flies (Diptera: Tephritidae). Handbooks for the Identification of British Insects 10 (5a), 1-134.

White, I.M. \& Clement, S.L. (1987) Systematic notes on Urophora (Diptera, Tephritidae) species associated with Centaurea 
solstitialis (Asteraceae, Cardueae) and other Palaearctic weeds adventive in North America. Proceedings of the Entomological Society of Washington 89, 571-580.

White, I.M. \& Korneyev, V.A. (1989) A revision of the western Palaearctic species of Urophora (Robineau-Desvoidy). Systematic Entomology 14, 327-374.

White, I.M. \& Marquardt, K. (1989) A revision of the genus Chaetorellia Hendel (Diptera: Tephritidae) including a new species associated with spotted knapweed, Centaurea maculosa Lam. (Asteraceae). Bulletin of Entomological Research, 79, 453-487.
Wiedemann, C.R.W. (1830) Aussereuropäische zweiflügelige Insekten. 2, 684 pp. Hamm.

Zwölfer, H. (1965) Preliminary list of phytophagous insects attacking wild Cynareae (Compositae) species in Europe. Technical Bulletin of the Commonwealth Institute of Biological Control No. 6, 81-154.

(c) C.A.B International, 1990 
